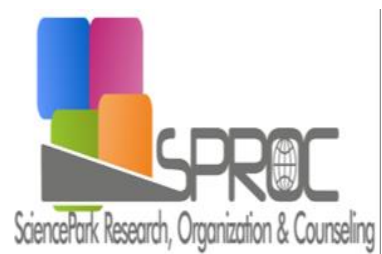

cetct I

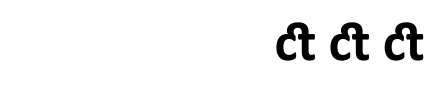

ctct I ct

ct ct

ct ct

!

Social Sciences.
D'New Trends

and Issues Proceedings

on Humanities and Social Sciences

$v$ ct w

ct ct

ct 1

ct

ct

New Trends and Issues Proceedings on Humanities and 
ct ct

2.1. Purpose

2.2. Study design

Study area

2.4. Sampling 
New Trends and Issues Proceedings on Humanities and Social Sciences.

\subsection{Data collection tools}




\subsection{Data collection and analysis}

\subsection{Ethical and legal aspects of the study}

$S$ ct $C$

ct ctet ct $w$ ct

ct ct

ct 
New Trends and Issues Proceedings on Humanities and Social Sciences.

$S$ ct $C$

ct ct ct ct ct $w$ ct

$S$ ct $C$ ct ct ct $w$ ct ct

ct

ct

ct ct $v$ ct ct ct ct ct ct ct

ct 
New Trends and Issues Proceedings on Humanities and Social Sciences. 
New Trends and Issues Proceedings on Humanities and Social Sciences. 


\title{
ctctct ct
}

TAF Preventive Medicine

Six Thinking Hats Technique

Australian Journal of Advanced Nursing 26

Asian Pacific

Journal of Cancer Prevention, 15

Hemsirelik Forumu

\begin{abstract}
AANA Journal
State-trait anxiety inventory handbook
\end{abstract}

I. Uluslararası, V.Ulusal Hemsirelik Egitimi Kongresi Bildiri Kitabı

International Nursing Review 52

Journal Dental Education 66

Res Nurs Health

Nursing Studies, 39

Nurse Education Today 34

C.U. Hemsirelik YUksekokulu Dergisi 